Supporting Information

\title{
Modeling of Membrane-assisted Seeded Batch
}

\section{Crystallization}

Po-Chen Su and Jeffrey D. Ward

Dept. of Chemical Engineering, National Taiwan University, Taipei 106-07, Taiwan 
Figures 

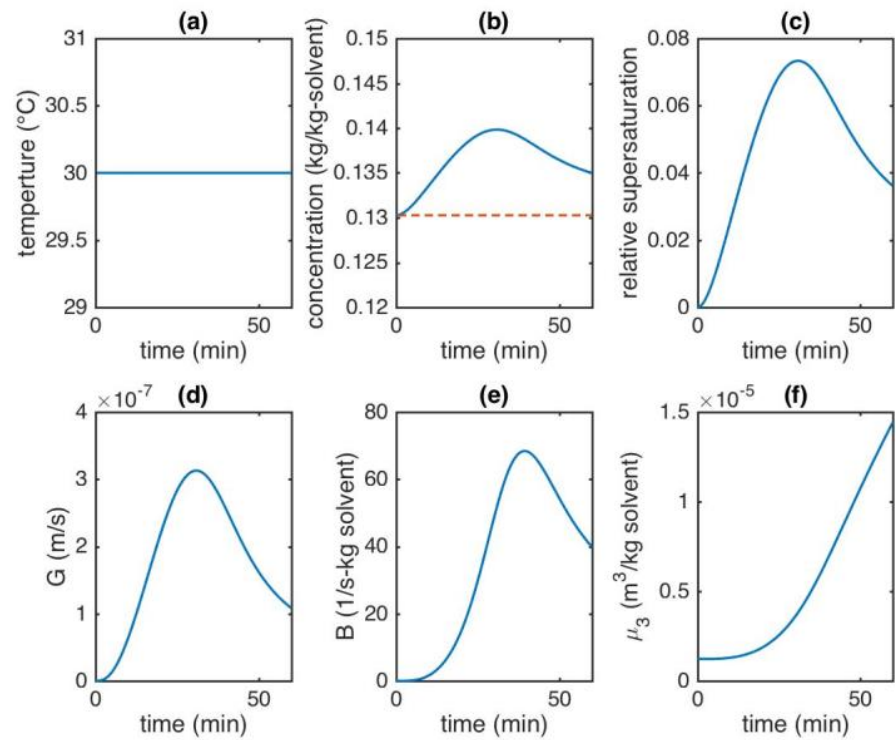

Figure S1. Dynamic results for the potassium sulfate process under base-case conditions (Table 2). (a) Temperature in the crystallizer. (b) Concentration in the crystallizer. (c) Relative supersaturation in the crystallizer. (d) Crystal growth rate. (e) Crystal nucleation rate. (f) The third moment of crystals in the crystallizer.
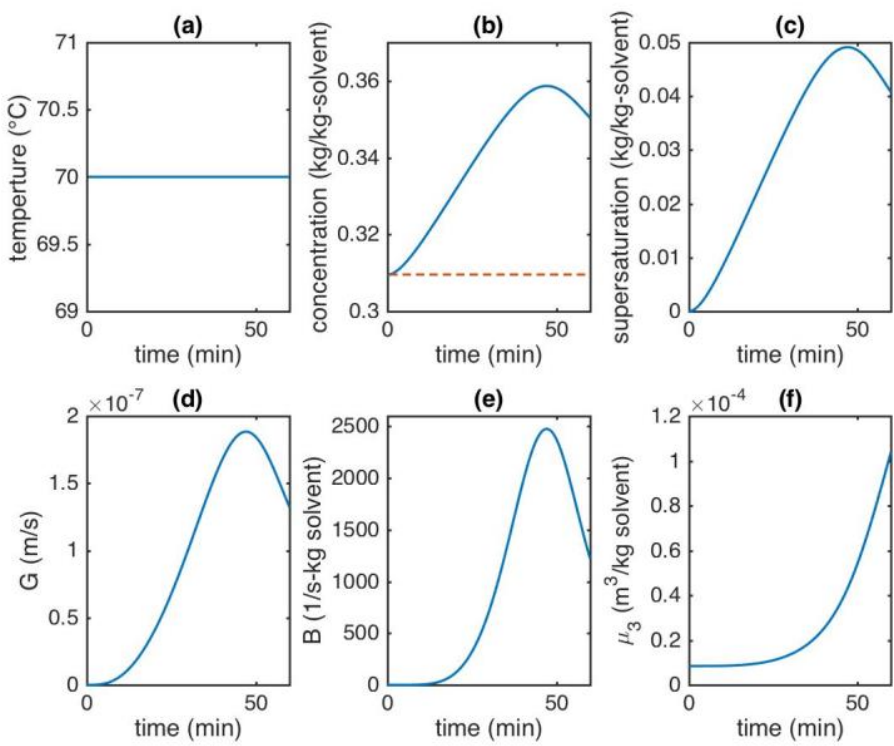

Figure S2. Dynamic results for the pentaerythritol process under base-case conditions (Table 2). (a) Temperature in the crystallizer. (b) Concentration in the crystallizer. (c) Relative supersaturation in the crystallizer. (d) Crystal growth rate. (e) Crystal nucleation rate. (f) The third moment of crystals in the crystallizer. 

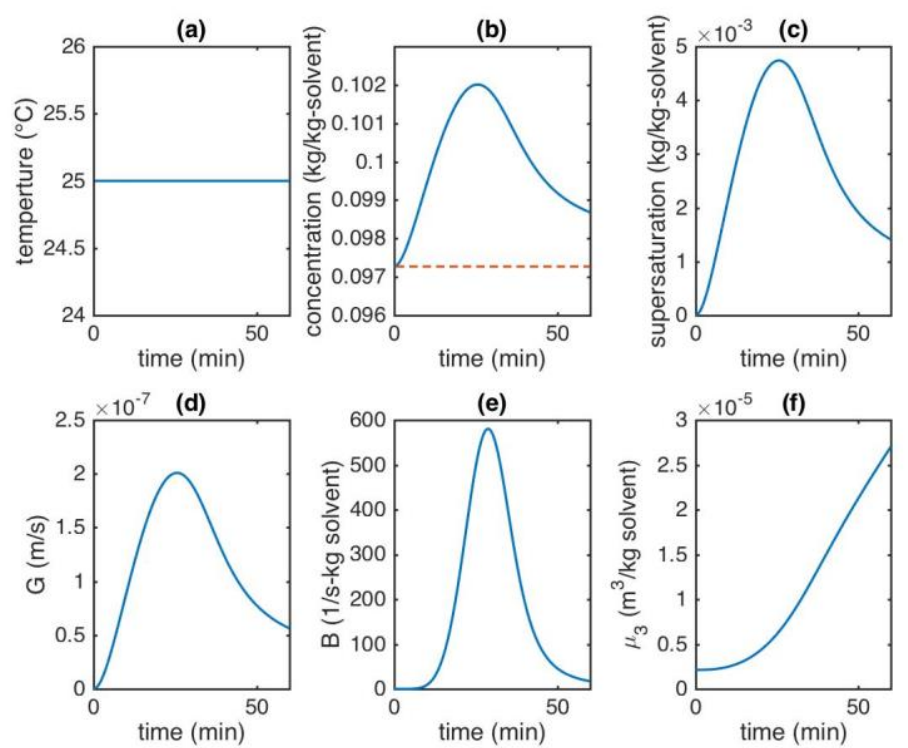

Figure S3. Dynamic results for the succinic acid process under base-case conditions (Table 2). (a) Temperature in the crystallizer. (b) Concentration in the crystallizer. (c) Relative supersaturation in the crystallizer. (d) Crystal growth rate. (e) Crystal nucleation rate. (f) The third moment of crystals in the crystallizer.
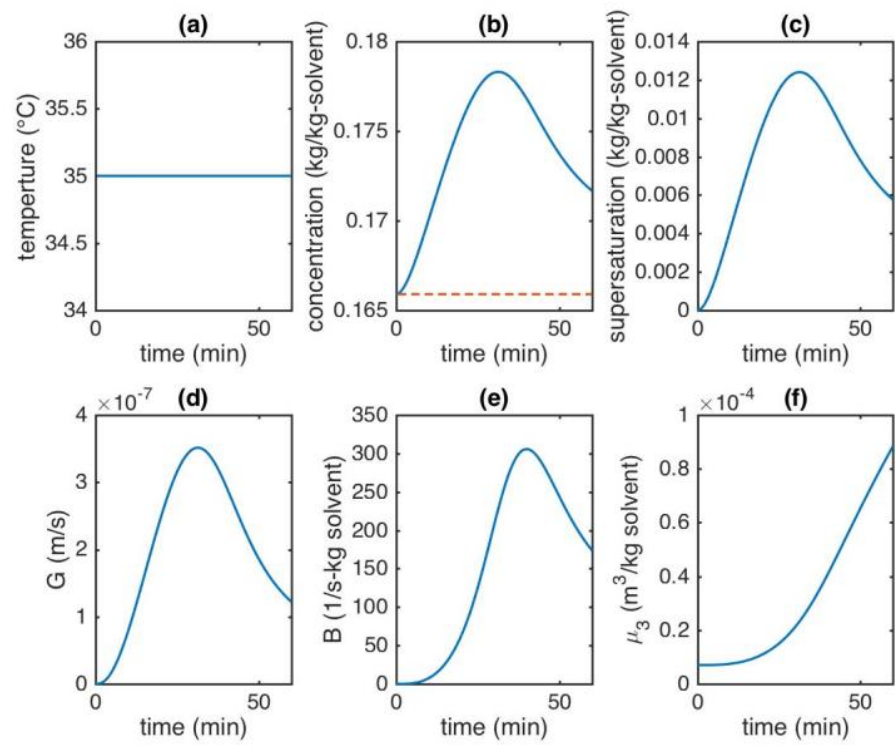

Figure S4. Dynamic results for the potassium alum process under base-case conditions (Table 2). (a) Temperature in the crystallizer. (b) Concentration in the crystallizer. (c) Relative supersaturation in the crystallizer. (d) Crystal growth rate. (e) Crystal nucleation rate. (f) The third moment of crystals in the crystallizer. 

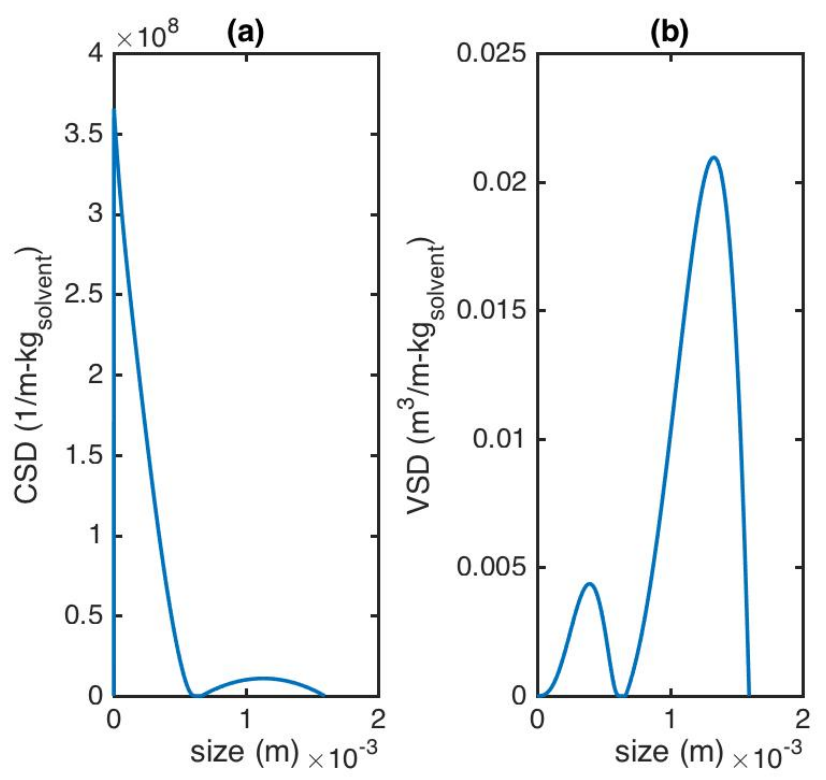

Figure S5. Final product crystal size distribution for the potassium sulfate process under base-case conditions. (a) Number size distribution. (b) Volume size distribution.
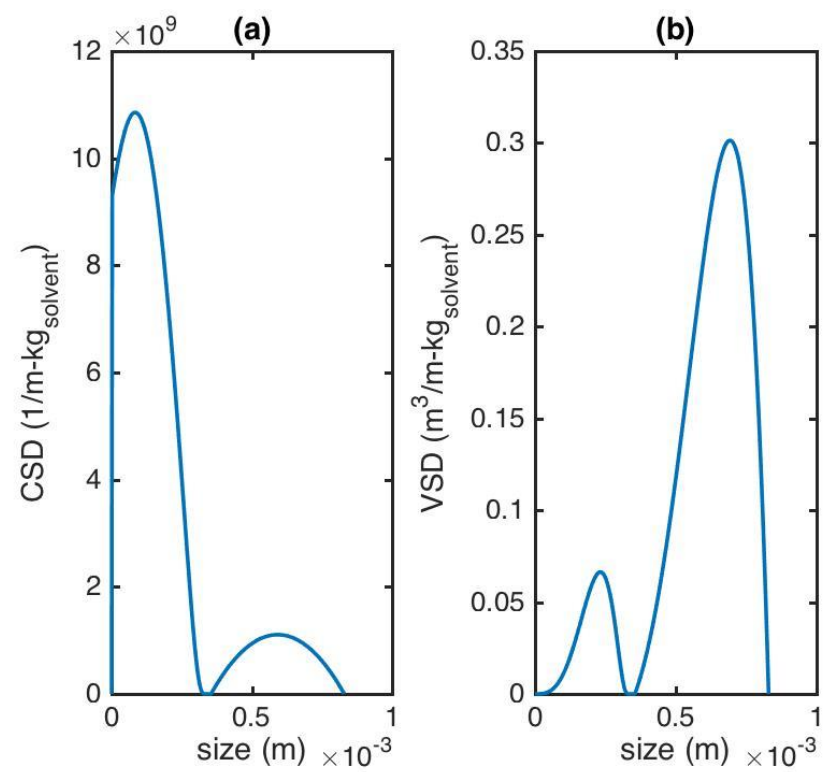

Figure S6. Final product crystal size distribution for the pentaerythritol process under base-case conditions. (a) Number size distribution. (b) Volume size distribution. 

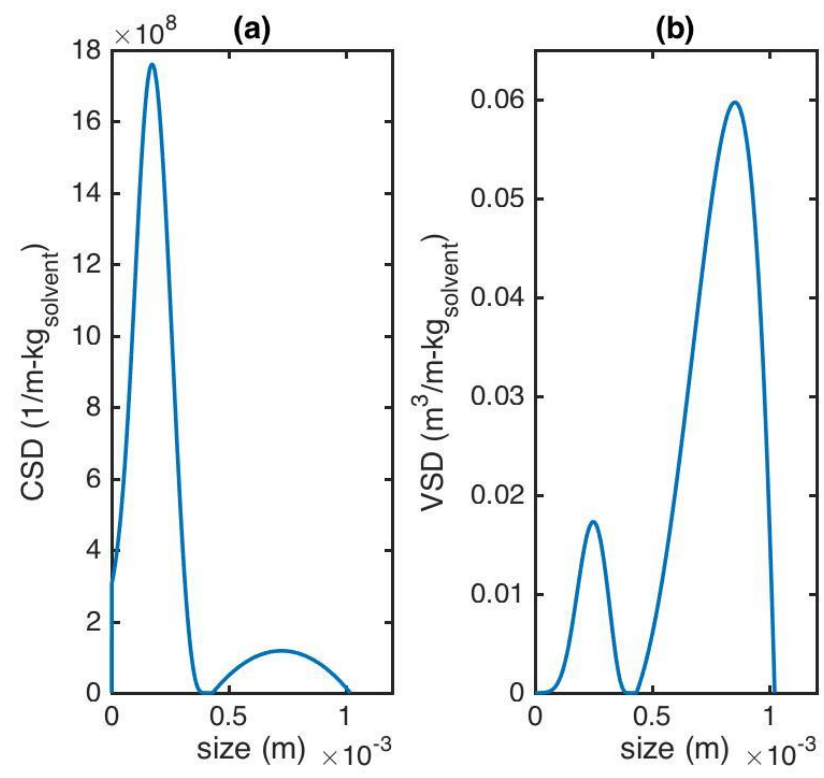

Figure S7. Final product crystal size distribution for the succinic acid process under base-case conditions.

(a) Number size distribution. (b) Volume size distribution.
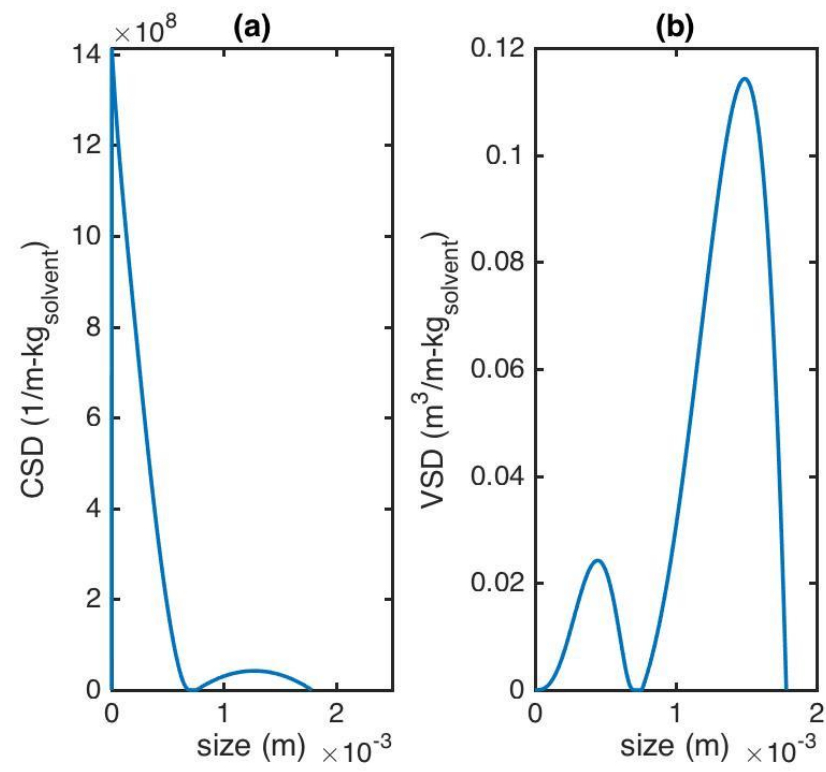

Figure S8. Final product crystal size distribution for the potassium alum process under base-case conditions. (a) Number size distribution. (b) Volume size distribution. 
(a)
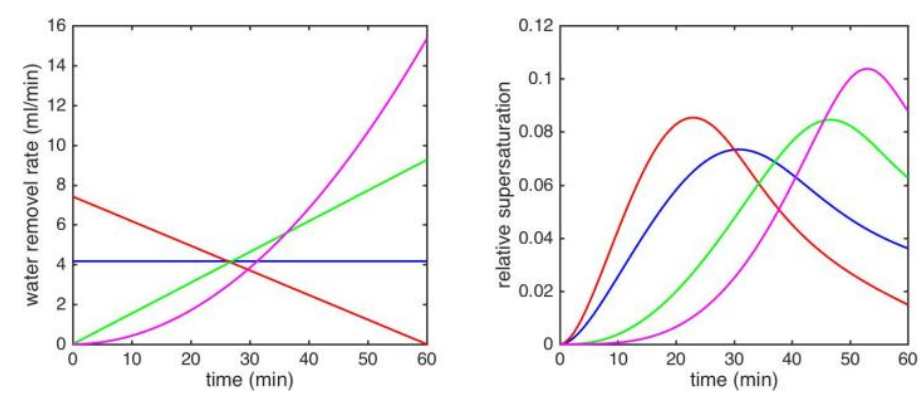

constant water removal rate

decreasing water removal rate

increasing water removal rate

quadratic increasing water removal rate (c)

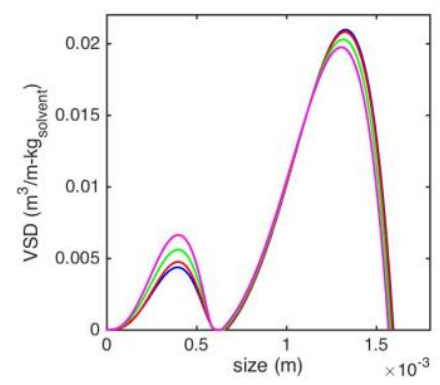

Figure S9. Effect of water removal rate strategy on relative supersaturation profile and product volume crystal size distribution for potassium sulfate. (a) Water removal rate. (b) Relative supersaturation. (c) Final volume size distribution.

(a)

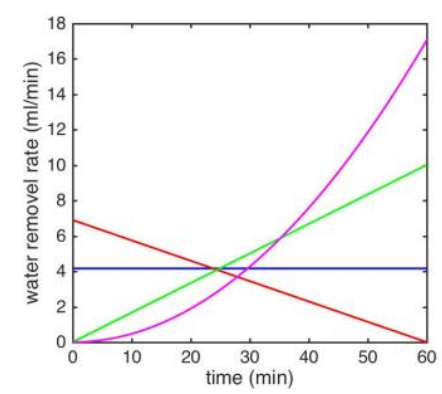

(b)

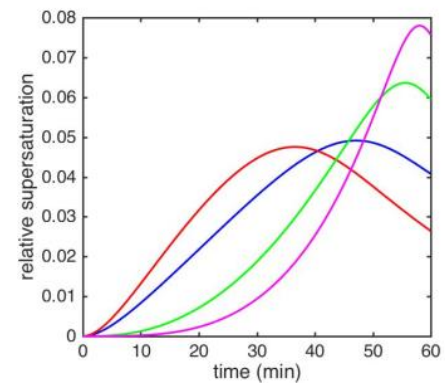

(c)

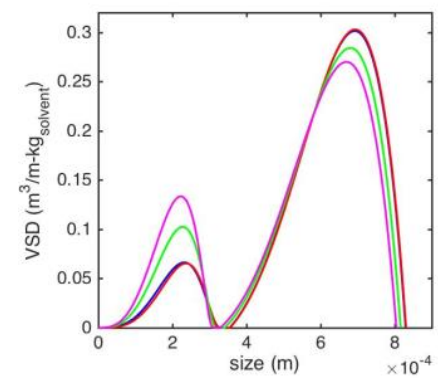

constant water removal rate decreasing water removal rate increasing water removal rate quadratic increasing water removal rate$$
\text { - }
$$

Figure S10. Effect of water removal rate strategy on relative supersaturation profile and product volume crystal size distribution for pentaerythritol. (a) Water removal rate. (b) Relative supersaturation. (c) Final volume size distribution. 
(a)

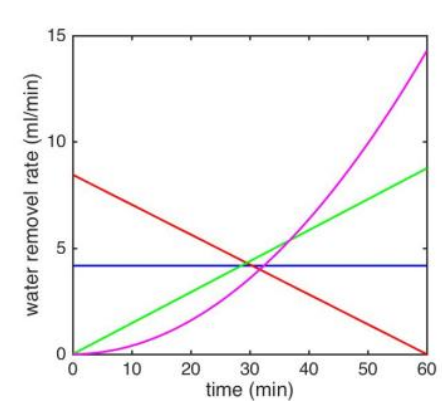

(b)

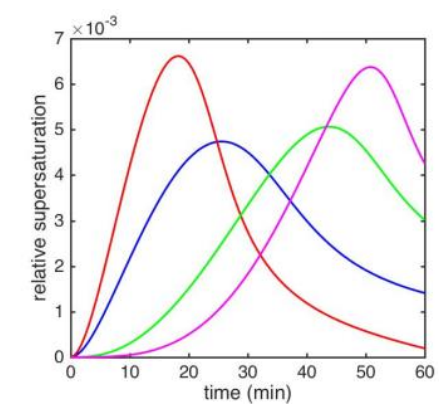

(c)

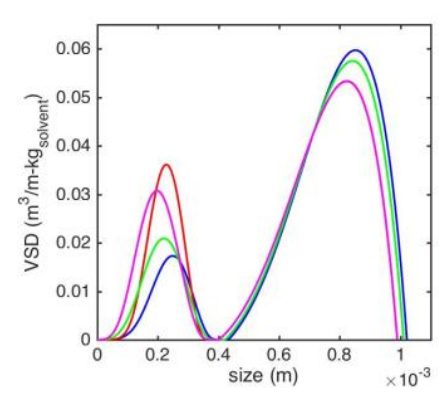

constant water removal rate

- decreasing water removal rate

increasing water removal rate

quadratic increasing water removal rate

Figure S11. Effect of water removal rate strategy on relative supersaturation profile and product volume crystal size distribution for succinic acid. (a) Water removal rate. (b) Relative supersaturation. (c) Final volume size distribution.

(a)

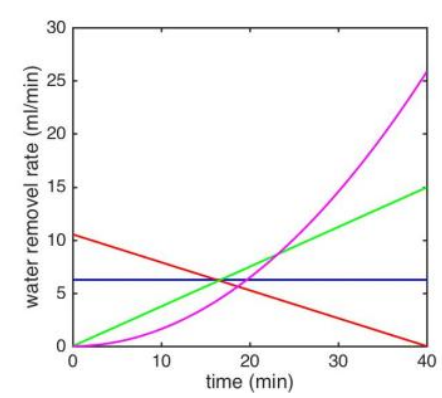

(c)

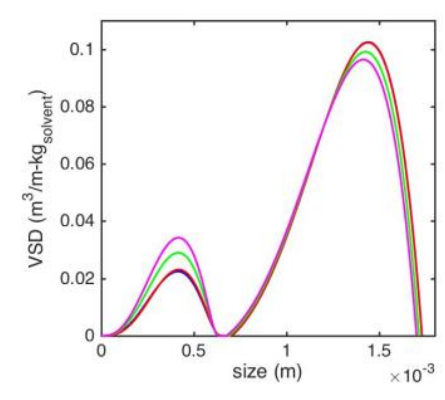

(b)

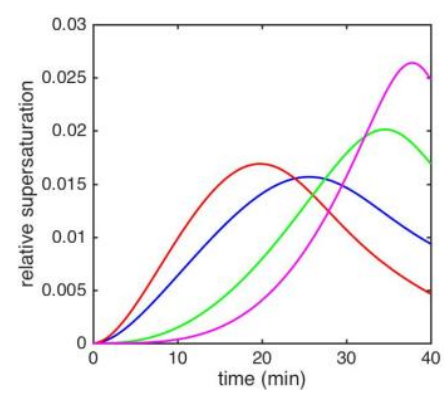

- constant water removal rate decreasing water removal rate increasing water removal rate quadratic increasing water removal rate

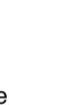

Figure S12. Effect of water removal rate strategy on relative supersaturation profile and product volume crystal size distribution for potassium alum. (a) Water removal rate. (b) Relative supersaturation. (c) Final volume size distribution. 

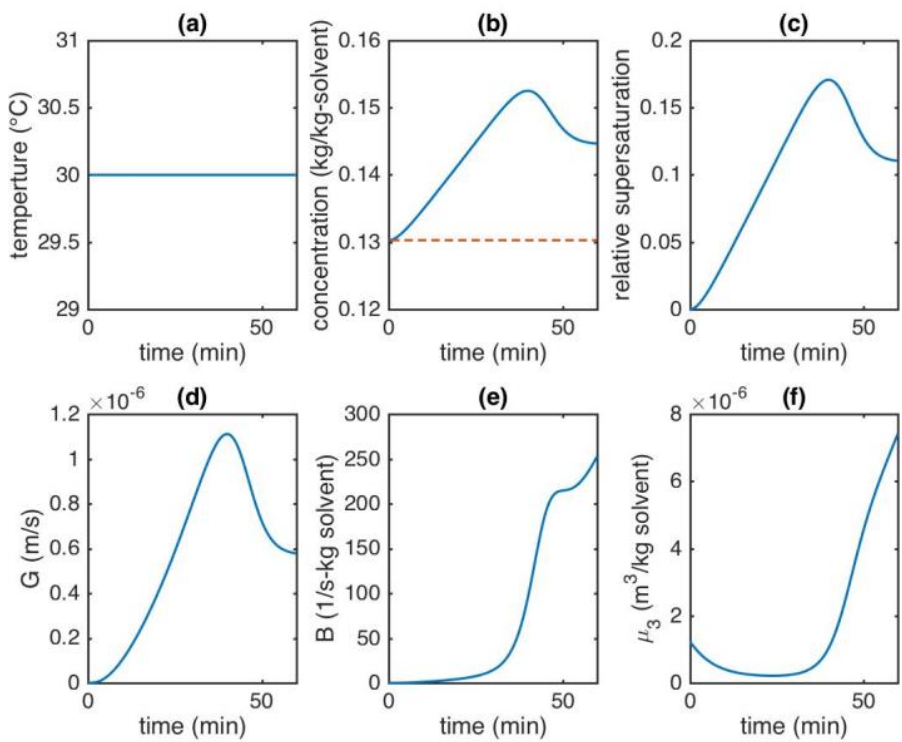

Figure S13. Dynamic results for the potassium nitrate sulfate with slurry removal. (a) Temperature in the crystallizer. (b) Concentration in crystallizer. (c) Relative supersaturation in the crystallizer. (d) Crystal growth rate. (e) Crystal nucleation rate. (f) The third moment of crystals in the crystallizer.
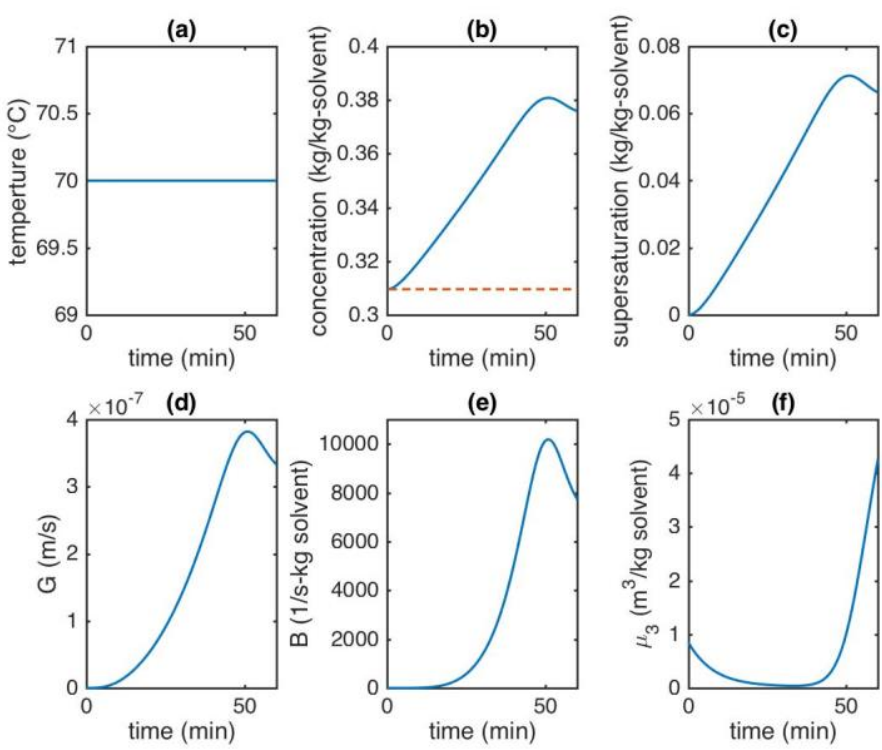

Figure S14. Dynamic results for the pentaerythritol process with slurry removal. (a) Temperature in the crystallizer. (b) Concentration in crystallizer. (c) Relative supersaturation in the crystallizer. (d) Crystal growth rate. (e) Crystal nucleation rate. (f) The third moment of crystals in the crystallizer. 

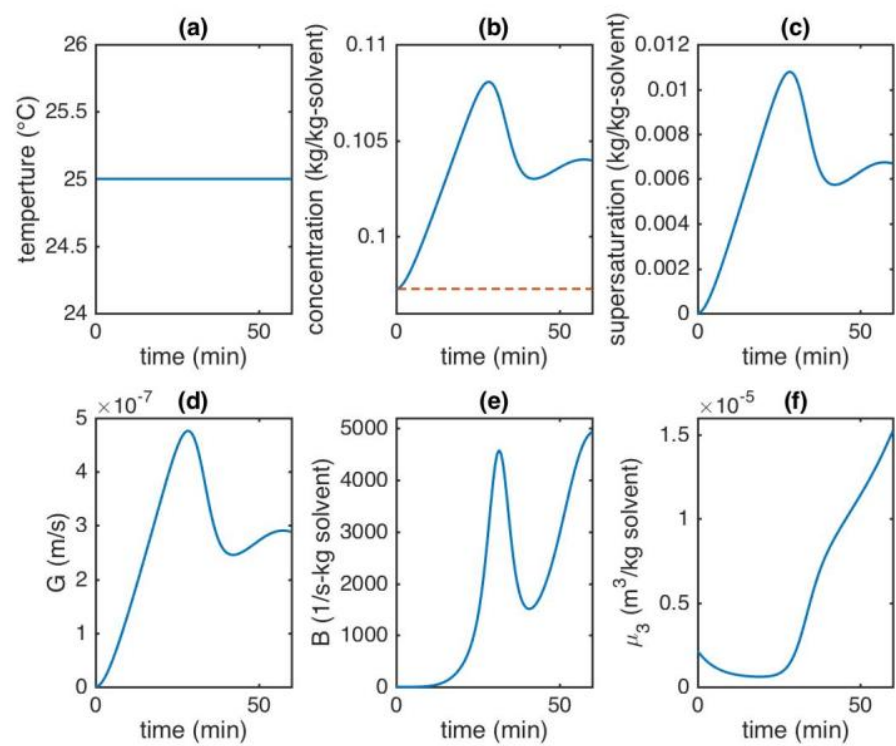

Figure S15. Dynamic results for the succinic acid process with slurry removal. (a) Temperature in the crystallizer. (b) Concentration in crystallizer. (c) Relative supersaturation in the crystallizer. (d) Crystal growth rate. (e) Crystal nucleation rate. (f) The third moment of crystals in the crystallizer.
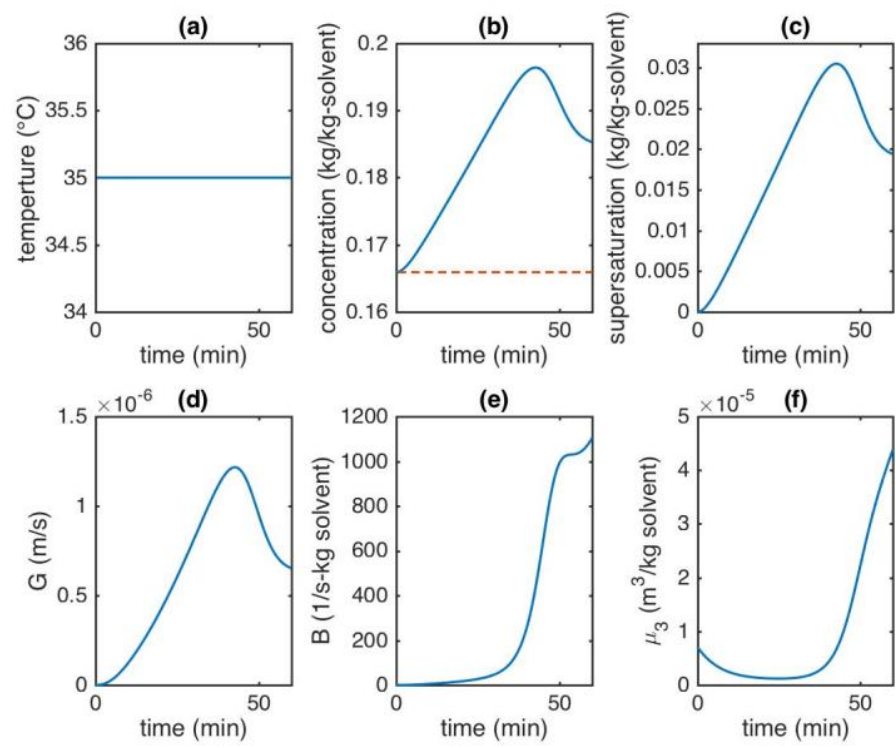

Figure S16. Dynamic results for the potassium alum process with slurry removal. (a) Temperature in the crystallizer. (b) Concentration in crystallizer. (c) Relative supersaturation in the crystallizer. (d) Crystal growth rate. (e) Crystal nucleation rate. (f) The third moment of crystals in the crystallizer. 

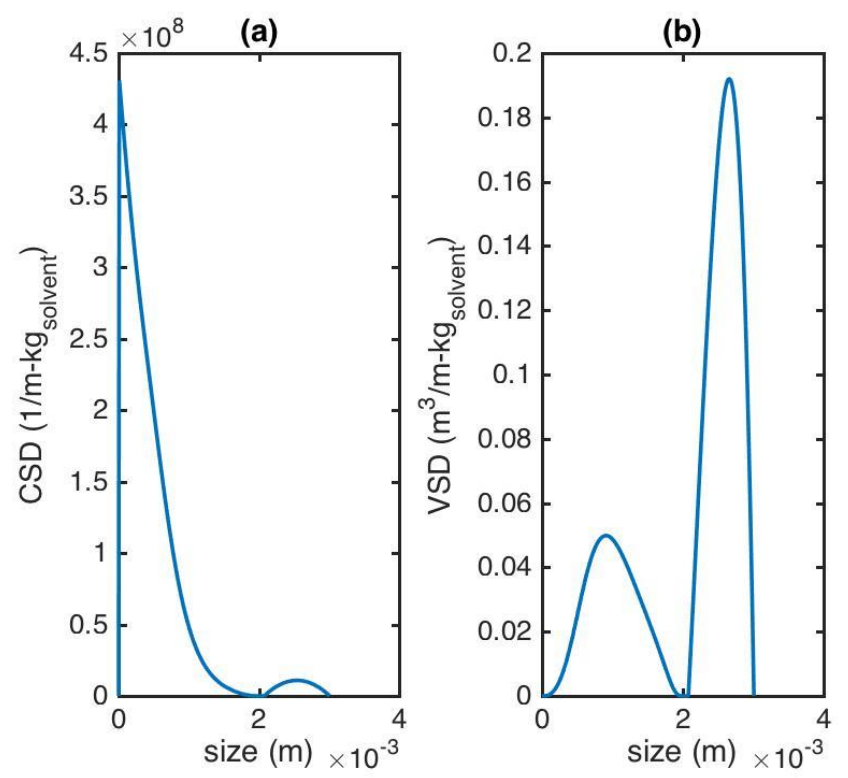

Figure S17. Product crystal size distribution for the potassium sulfate process with slurry removal. (a) Number size distribution. (b) Volume size distribution.
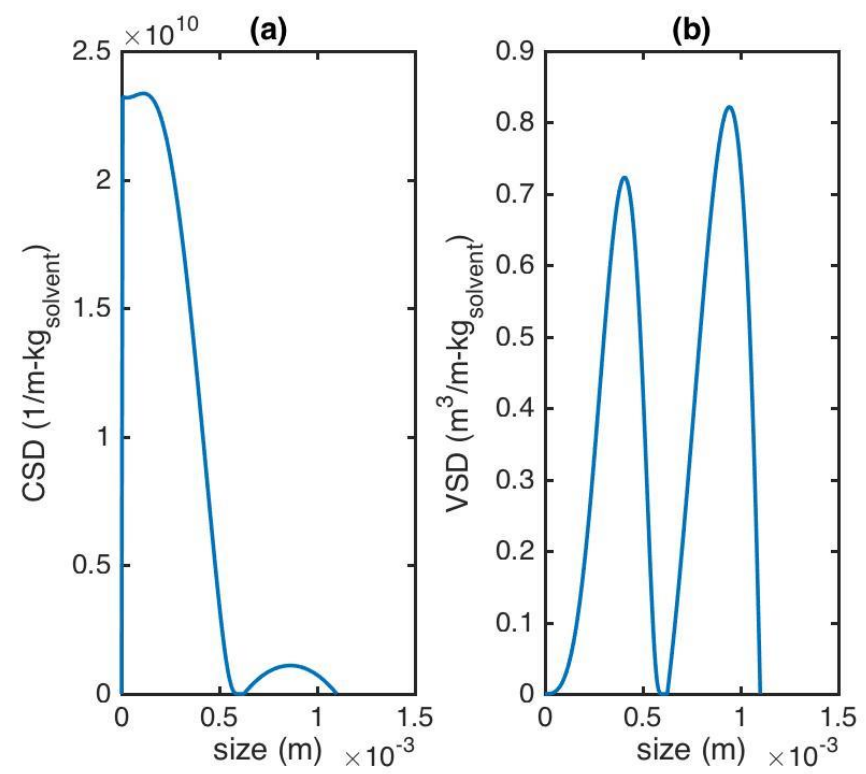

Figure S18. Product crystal size distribution for the pentaerythritol process with slurry removal. (a) Number size distribution. (b) Volume size distribution. 

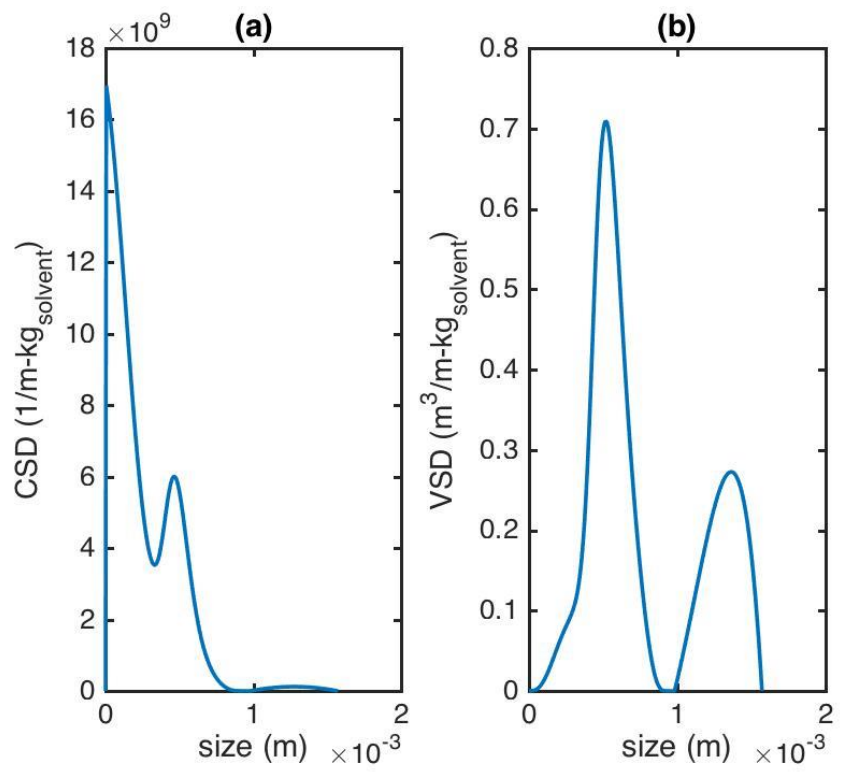

Figure S19. Product crystal size distribution for the succinic acid process with slurry removal. (a) Number size distribution. (b) Volume size distribution.
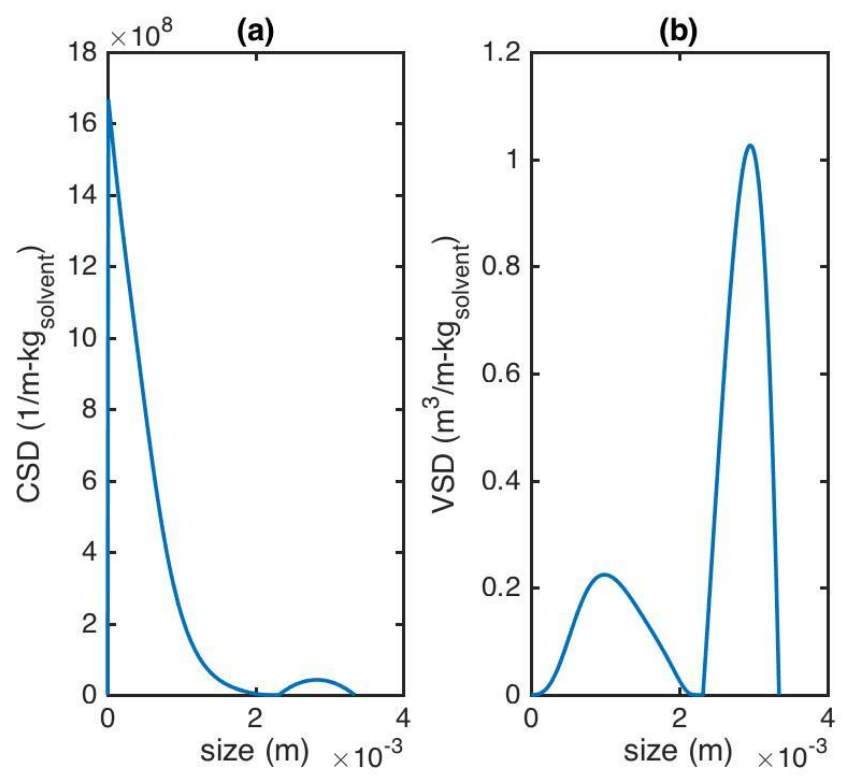

Figure S20. Product crystal size distribution for the potassium alum process with slurry removal. (a) Number size distribution. (b) Volume size distribution. 